\title{
SUNSHINE RECORDS FROM IRELAND: CLOUD FACTORS AND POSSIBLE LINKS TO SOLAR ACTIVITY AND COSMIC RAYS
}

\author{
E. PALLÉ* and C.J. BUTLER \\ Armagh Observatory, Armagh, Northern Ireland \\ Received 30 May 2000 \\ Revised 3 January 2001 \\ Accepted 26 January 2001
}

\begin{abstract}
The records of sunshine hours obtained since the late 19th century from four stations distributed throughout Ireland were analysed. A gradual decrease in sunshine hours has occurred at all four sites since records began. Increasing cloud factors, resulting from enhanced evaporation rates over the Atlantic as sea surface temperatures have risen, is one possible explanation for the decline in sunshine.

A strong negative correlation was confirmed between sunshine factors from ground-based observations and satellite-based cloud factors over Ireland. In addition, it was found that cloud factors over Ireland correlated well with cloud factors over large oceanic areas such as the North Atlantic and mid-high latitudes generally. Thus cloud factors (and similarly sunshine factors) from regions on the boundaries of large oceans which lie in the direction of the prevailing wind could be useful in determining the long-term changes in cloud factors over more extended areas. Knowledge of such long term variability in the Earth's cloud cover is important input information for modelling past climate change.

The importance of cosmic rays as a link between solar activity and climate was assessed from a study of the ISCCP-D2 satellite cloud factors and Irish sunshine data. Whilst these results confirmed the strong correlation between total cloud factor and cosmic rays over non-tropical oceans between 1984 and 1991 previously reported, it was found that this correlation did not hold in the subsequent period 1991-1994. Other work has established a link through specifically low cloud.

Indirect evidence of cloud formation by cosmic rays from a variation in the sunshine factor following Forbush decreases, and over the sunspot cycle, was mostly negative. Although a dip at seven years past sunspot minimum is evident in the sunshine factor for all four sites and in most seasons, it is of marginal statistical significance. Copyright (C) 2001 Royal Meteorological Society.
\end{abstract}

KEY WORDS: clouds; correlation; cosmic rays; Ireland; North Atlantic; solar activity; sunshine; trends

\section{INTRODUCTION}

In spite of much discussion in the literature over the past decade the physical process whereby solar activity may affect climate remains unresolved. Amongst the various processes that have been proposed one of the most promising is the effect of solar activity on terrestrial clouds.

It is well known that solar activity disturbs the interplanetary magnetic field and this causes a modulation in the cosmic ray flux reaching the Earth which is strongly anti-correlated with the sunspot number. If the cosmic ray flux were to affect cloud formation on Earth, it could provide a mechanism linking solar activity and climate via changes in albedo and the Earth's infra-red emission.

This suggestion received support from a study of global satellite cloud cover data which indicated a highly significant correlation between cosmic ray flux and cloudiness over the mid-latitude oceans (Svensmark and Friis-Christensen, 1997; Svensmark, 1998). The variation of cloudiness during a single

* Correspondence to: Armagh Observatory, College Hill, Armagh BT61 9DG, Northern Ireland; e-mail: epb@star.arm.ac.uk; cjb@star.arm.ac.uk

Copyright (C) 2001 Royal Meteorological Society 
sunspot cycle was found to be of the order of $4 \%$, in the sense that increased cloudiness accompanied an increase of the cosmic ray flux and a decrease in solar activity.

However, the role of clouds in the climate is not clear. They have two opposite effects, a cooling effect reflecting solar radiation back into space and a warming effect through the trapping of the longwave emission from the Earth. It seems that, on average, clouds tend to cool the Earth (Ramanathan et al., 1989), so a decrease in the cloud factor should lead to an increase in temperatures. However, this cooling effect strongly depends on the type and altitude of the clouds, some of them even having an overall warming effect. Other problems with cloud cover are the difficulty of measurement and the short period covered by the datasets. Several authors have criticized the Svensmark and Friis-Christensen (1997) and Svensmark (1998) results on the grounds of inadequate calibration of the satellite data used and lack of a clear physical mechanism (see Kernthaler et al., 1999; Kristjansson and Kristiansen, 2000).

Satellite-based observations of cloud cover have been made only in recent decades. However, the number of hours of sunshine has been recorded at various sites since the installation of Campbell-Stokes sunshine recorders in the second half of the 19th century. Naturally, there is a strong seasonal variation, but in principle, averaged over the year, the number of hours of sunshine should give us, on time scales of decades or centuries, indirect information on the cloud cover. The main problem with this cloud-proxy, is that the sunshine record does not give us any information about the cloud type or their altitude. It can also be noted that, for a single place, the number of hours of sunshine can also be affected by local site-specific errors, for example atmospheric pollution (Dukes and Eden, 1997). In addition, volcanic eruptions will affect the sunshine records (Lamb, 1977) but hopefully in a way that can be easily distinguished from longer term trends.

The proximity of Ireland to the Atlantic Ocean and the prevailing westerly winds at these latitudes, suggested to the authors that perhaps cloud modulation over the Atlantic could give rise to an inverse modulation of total sunshine hours in Ireland.

This paper has two objectives. Firstly, an assessment was made of the usefulness of sunshine measurements in Ireland as a proxy for cloud cover, not only over Ireland but also over more extended regions, such as the north Atlantic and mid-high latitudes generally (Sections 3,4 and 5). The second goal was to search for fingerprints of solar activity on the sunshine records. In particular, the sunshine records were used to test the hypothesis that cosmic rays affect cloud cover (Sections 8 and 9). We have also identified a possible correspondence between the number of sunshine hours and the solar cycle length.

\section{DATA}

Daily records of the duration of bright sunshine were obtained at four stations in Ireland from May 1880 using a standard Campbell-Stokes sunshine recorder (Observers Handbook, 1982). Two are located (see Figure 1) in the east of Ireland; at Armagh Observatory and The Ordnance Survey Office, Phoenix Park, Dublin; one in the extreme west at Valentia Island/Cahirciveen, Co Kerry; and the fourth, in the midlands, at Birr Castle, Co Offaly. The Valentia Island Observatory was moved from the island to its present location 1 $\mathrm{km}$ south-west of Cahirciveen in March 1892. Data from Kew (southeast England), have also been used for comparison. Whilst the data for many other sites in the United Kingdom are in principle available, this is the only other long duration data set which was obtainable in suitable digital form. Data over a more limited period are available for research purposes from the British Atmospheric Data Centre, Rutherford Appleton Laboratory, Oxfordshire, UK (http://www.badc.rl.uk).

The data used in this study were monthly total sunshine hours as measured by the observer at each site. The Armagh Observatory data were taken from the Observatory Archives (Butler and Hoskin, 1987) and the data for the three stations in the Republic of Ireland were kindly provided by the Meteorological Office, Dublin.

All these data were as recorded and were not corrected for any changes in sensitivity of the equipment or changes in local conditions, such as the height of the local horizon. Nevertheless, the high degree of consistency that was found between the data from the four sites indicated that any such corrections were likely to be small. 


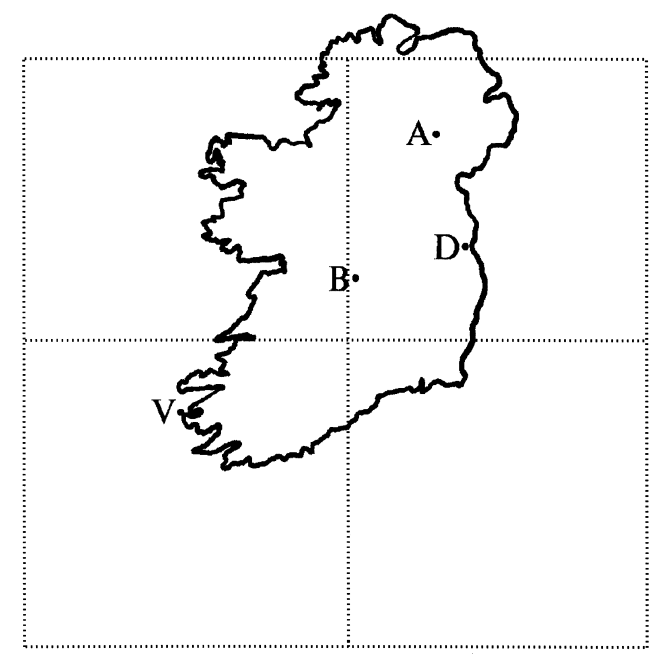

Figure 1. Outline map of Ireland. The geographical locations of the four Irish stations (A, Armagh; D, Dublin; B, Birr; V, Valentia) are shown, and the four areas covered by the satellite observations of cloud factor are indicated

The mean daily duration of bright sunshine at these latitudes contains strong seasonal components due to the variation in the length of daylight through the year and seasonal changes in meteorological conditions. In order to reduce these seasonal effects, we used sunshine factor, defined as the total measured hours of bright sunshine divided by the length of the period during which the sun lies more than $3^{\circ}$ above the horizon (the altitude at which the strength of the focused beam is sufficient to register on the recording chart).

In the Birr monthly mean sunshine records there were occasional omissions. These occurred in: January, February and August 1919; July-December 1922; and April and May 1923. In order to complete the series for statistical purposes, such as trend analysis etc., we inserted replacement data points which are the mean of the values for the same month, in the five years previous to and the five years following the year with missing data. The interpolated values only affected a total of 11 months (over 120 years) in the Birr data. In the archival records for Armagh, some sunshine data for 1883 is missing. Consequently, we did not use the Armagh data for this year in our analysis.

In addition to the monthly data for the five stations, we also employed the daily sunshine hours for Armagh which was entered onto computer for the years 1951-1998.

In our discussion of the cause of sunshine variation and its usefulness as an instrumentally-measured proxy for cloudiness, we employed both satellite cloud data from the International Satellite Cloud Cover Project (ISCCP) (Rossow et al., 1996) and synoptic cloud estimates for Armagh from 1951 to 1988. The latter data are visual estimates by observers at 09:00 GMT, expressed in oktas. Though such cloud data have been measured at Armagh and some other Irish stations since 1884, the complete series is not yet available in digital form. A programme to compile this and a number of other meteorological data series from Armagh into computer readable form is currently in progress and will eventually allow a full comparison of ground-based cloud estimates and sunshine data for this site from the late 19th century.

\section{CORRELATION OF SUNSHINE FACTORS BETWEEN SITES AND SEASONAL VARIATION IN SUNSHINE OVER IRELAND}

The four meteorological stations lie between approximately $52.0^{\circ}$ and $54.3^{\circ} \mathrm{N}$, and $6.3^{\circ}$ and $10.3^{\circ} \mathrm{W}$. Thus, although there is likely to be a strong degree of correlation between the sunshine records of the four sites, regional differences will occur. The correlation coefficients for the annual total sunshine hours at the four 
Table I. The correlation coefficient between the mean annual sunshine hours over the four Irish sites and Kew (England)

\begin{tabular}{lllll}
\hline & Armagh & Valentia & Dublin & Birr \\
\hline Armagh & - & $0.55(367)$ & $0.74(116)$ & $0.69(175)$ \\
Valentia & $0.55(367)$ & - & $0.71(317)$ & $0.76(212)$ \\
Dublin & $0.74(116)$ & $0.71(317)$ & - & $0.76(113)$ \\
Birr & $0.69(175)$ & $0.76(212)$ & $0.76(113)$ & - \\
Kew & $0.55(612)$ & $0.34(750)$ & $0.56(510)$ & $0.52(600)$ \\
\hline
\end{tabular}

All coefficients are significant at the $99.9 \%$ level or higher (less than $0.1 \%$ probability of occurrence by chance). The distance between the sites in kilometres is indicated in parentheses.

locations are listed in Table I and the data for one such pair, namely Armagh and Dublin, are shown in Figure 2. A high degree of correlation between the data for the different sites is evident though, as expected, this becomes less significant as the distance between the sites increases. Table I shows the correlation with the data for Kew Observatory near London, UK, over the years in common (1881-1964). The degree of correlation between the Kew and Irish sites clearly reduces as their separation increases.

Figure 3 shows the mean daily sunshine hours, the total available sunshine hours and the sunshine factor at Armagh, throughout the year, for the period 1951-1995. The double-humped nature of the sunshine factor curve is probably due to the pronounced shift in the atmospheric circulation pattern that often occurs in the British Isles in mid-June (Kelly et al., 1997) and which gives rise to an increasing dominance of westerly air-flows and a consequent fall in sunshine factor in July and August.

Figure 4 shows the mean daily maximum and minimum temperatures at Armagh for the same period (Butler and Johnston, 1996) and the monthly mean sea surface temperature (SST) for the North Atlantic Ocean for the period (1985-1998), as obtained by the Advanced Very High Resolution Radiometers (AVHRR) on board satellites NOAA-7-9-11 and 14 (Casey and Cornillon, 1999). The rapid rise in sunshine hours in the first half of the year is striking when compared to the more gradual rise in air temperature at Armagh which does not reach a maximum till late July, a full two months later than the maximum in sunshine hours. The maximum in SST occurs later still, reaching its peak in mid-late August. It is evident that both maximum and minimum temperatures in Ireland reflect the combined effects of local sunshine variation and the sea-surface temperature variation of the Atlantic.

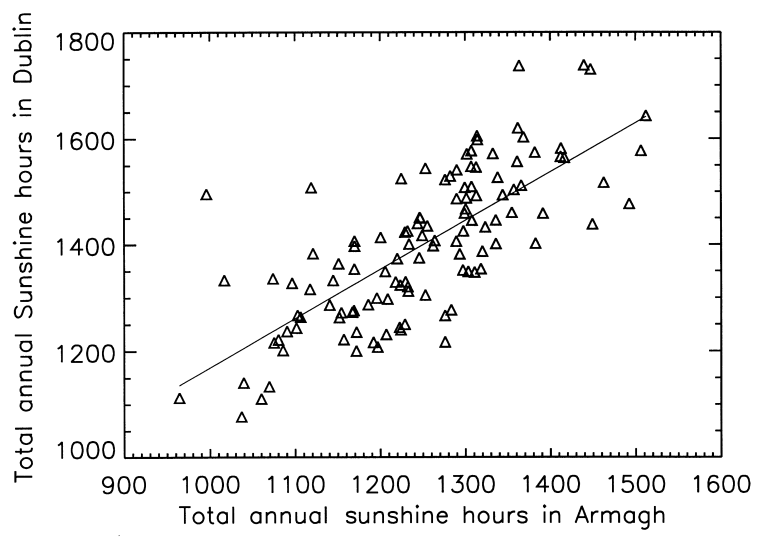

Figure 2. The number of hours of sunshine in Armagh and Dublin (correlation coefficient 0.74). The plotted line is a least squares fit to the points 

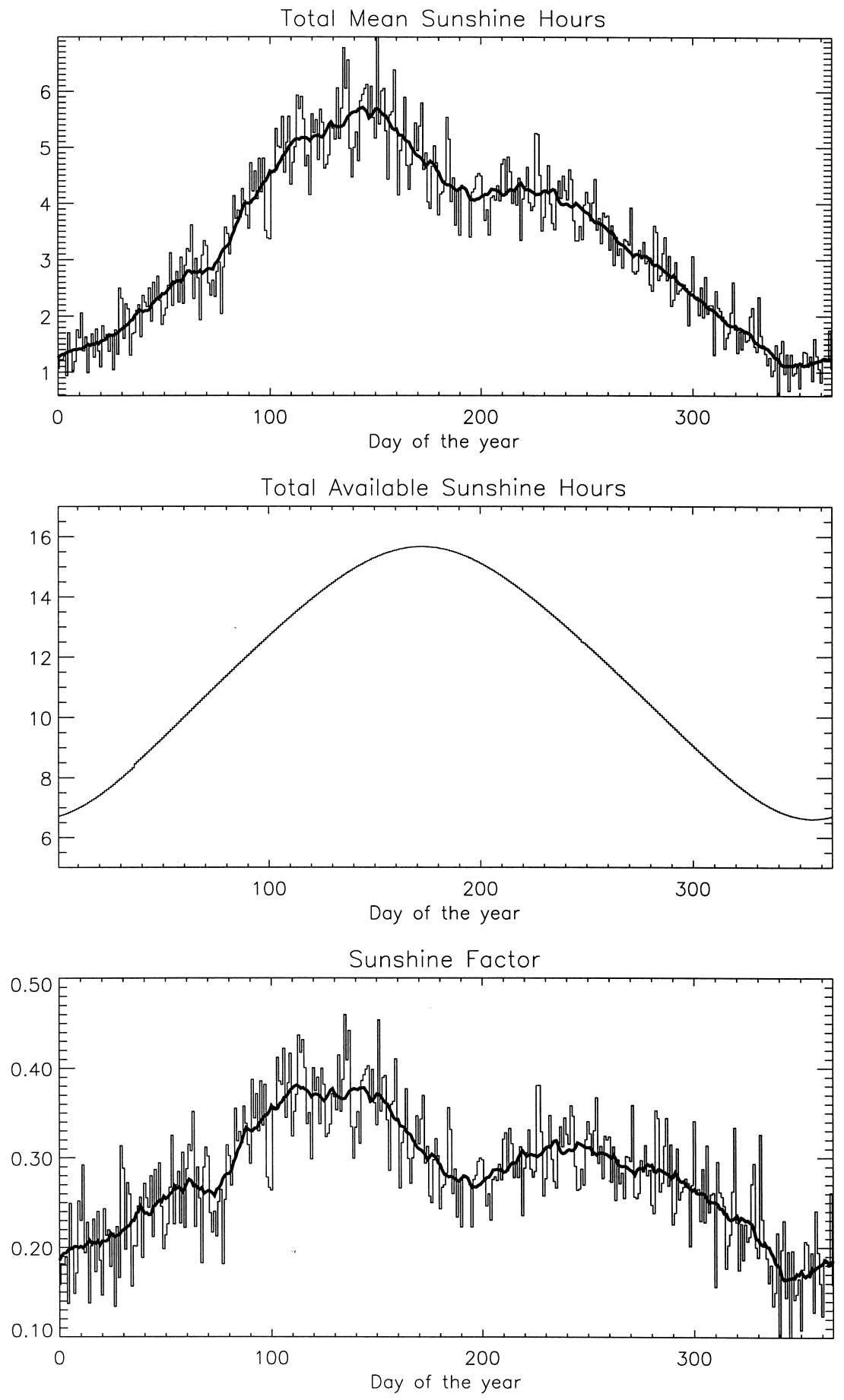

Figure 3. Top: mean daily number of hours of sunshine at Armagh Observatory for the period 1951-1995. Middle: total available sunshine hours in Armagh. Bottom: sunshine factor. The thick line shows a seven point running mean 


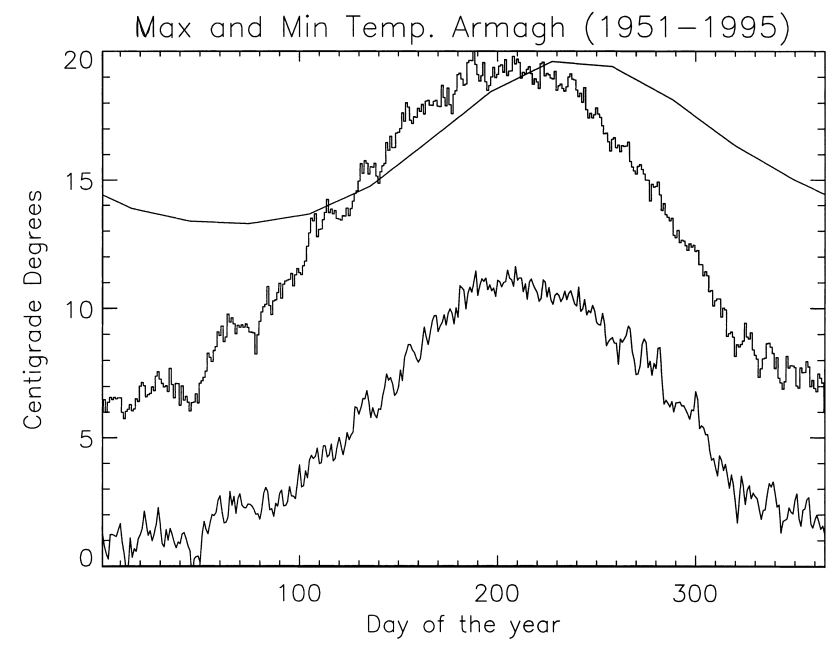

Figure 4. Mean daily averaged maximum and minimum temperatures at Armagh Observatory for the period 1951-1995 and the mean sea-surface temperature for the North Atlantic for 1985-1998. (NSIPP AVHRR Data Archive, http://mohawk.gsfc.nasa.gov/avhrr/)

\section{OVERALL TRENDS IN SUNSHINE OVER IRELAND}

Figure 5 shows the total number of hours of bright sunshine for the four Irish sites for the period 1881-1998. The most prominent feature of the data, for all four sites, is a gradual decline in the total annual sunshine hours over much, if not all, of the 117 year period during which records have been obtained. The effect is particularly conspicuous at the most westerly site of Valentia Island/Cahirciveen, on the County Kerry coast, where the number of sunshine hours has dropped by $\sim 20 \%$ since the end of
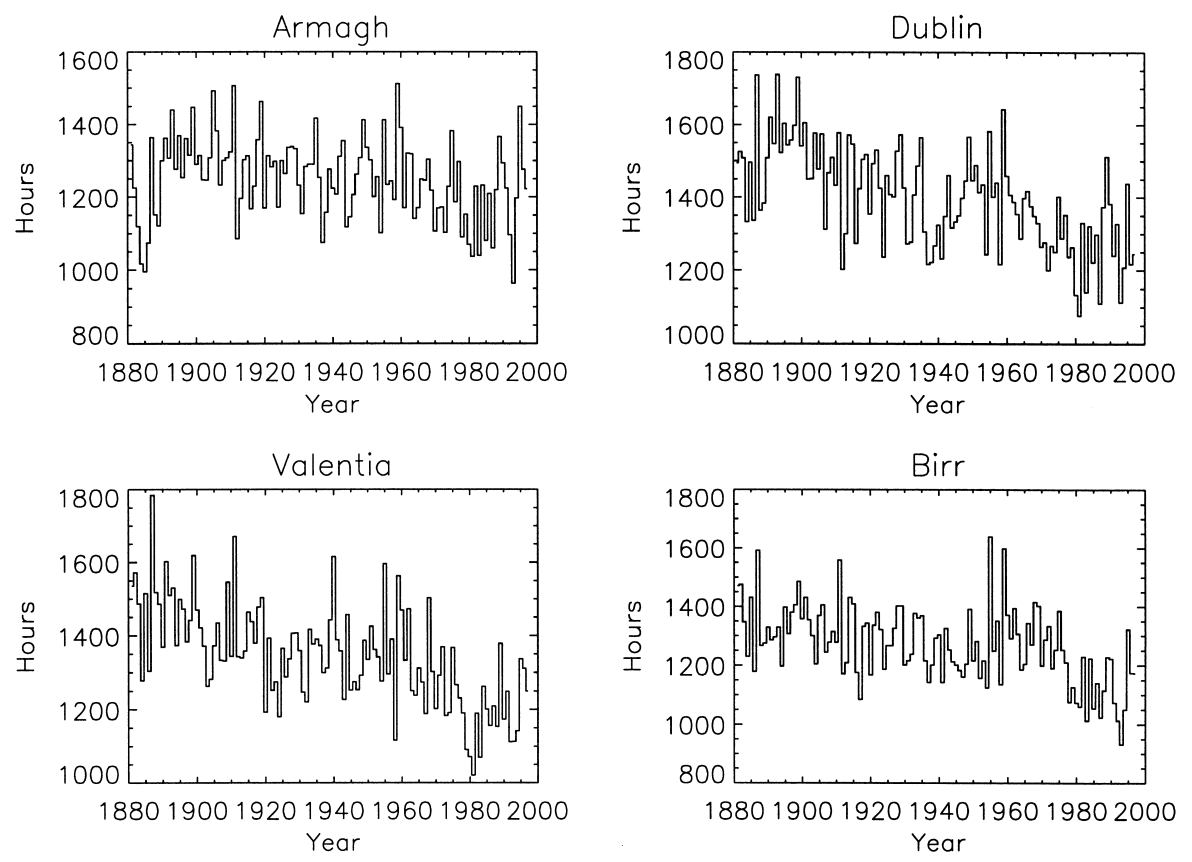

Figure 5. Total annual sunshine hours for four Irish sites 1881-1998 
the last century. If we plot the seasonal averages, the gradual decrease is seen in all stations in most seasons.

Stanhill (1998) reported a decrease in direct and diffuse radiation at six Irish sites during the second half of the twentieth century. Interestingly, at Valentia, where the study was most complete, the global irradiance dropped significantly over the four decades considered, but there was no significant trend in the cloud cover (as estimated visually by observers). However, a significant negative correlation was found between the inter-annual irradiance measurements and cloud cover which suggested that, although cloud cover has a major influence on irradiance variation, other factors such as atmospheric turbidity may play a part in explaining long term trends.

It is possible to test this suggestion by comparing the reduction in bright sunshine observed at Valentia with that predicted from the known increase in anthropogenic aerosols. It was found that the sunshine factor decreased by an order of magnitude greater than would be expected from the known concentration of sulphate aerosols in this relatively unpolluted region. Thus it was concluded that an increase in aerosols is unlikely to be the cause of the sunshine decrease. In order to investigate further the cause of the systematic decline in sunshine over Ireland since the late 19th century, we next looked at the evidence for a change in the cloud factor from Armagh synoptic observations.

\subsection{Synoptic observations of cloudiness and comparison with the duration of bright sunshine}

Figure 6 shows the annual variation in cloud factor at 09:00 GMT from 1951 to 1987 together with the total annual sunshine hours over the same period for Armagh Observatory. Superimposed on each plot is the trend determined by a least squares method. A 15\% increase in cloud cover was found over this period, compared with a $13.5 \%$ decrease in sunshine. These trends are so similar that it could be concluded that, contrary to Stanhill's result, an increase in cloud cover is the most likely cause of the drop in sunshine over Ireland since the late 19th century.

Comparisons between synoptic cloud records and sunshine duration have been made in several areas of the world. Angell et al. (1984) and Angell (1990) compared cloud and sunshine records for the United States for the period 1950-1988, and found a decrease in sunshine hours accompanied by an increase in cloud cover. A strong negative correlation between the two datasets was reported, even though the magnitude of the increase in cloud cover was greater than the decrease in sunshine records. This result was attributed to an increase in thin cirrus clouds which were not thick enough to interrupt the sunshine record but nonetheless were included in the cloud report. Chagnon (1981) found virtually the same results for the midwest United States during the period 1901-1977. Raju and Kumar (1982) argued that the fraction of possible sunshine will closely approximate the fraction of possible clear weather when averaged over long term periods in any given region, and they demonstrated how sunshine derived cloud cover in India can be considered a better measurement of actual cloud cover than visual estimates of cloudiness.

Evidence has accumulated from several parts of the world, for example: North America (Henderson-Sellers, 1989); Australia (Jones and Henderson-Sellers, 1992); Estonia (Russak, 1990); the former Soviet Union (Sun and Groisman, 2000) and oceans (Norris, 1999) that global cloud cover is gradually increasing. Thus our results for Ireland are very much in line with those found elsewhere. A decline in sunshine hours of this nature, in a region close to a large ocean, might be expected to arise from an increase in evaporation rates following the rise in sea-surface temperatures which has accompanied global warming (Reid, 1987). A comparison of atmospheric water vapour over tropical $\left(20^{\circ} \mathrm{S}-20^{\circ} \mathrm{N}\right)$ and extra-tropical $\left(20^{\circ}-60^{\circ} \mathrm{N} \& \mathrm{~S}\right)$ oceans with SSTs by Wentz and Schabel (2000) confirmed that an increase in total column water vapour content has accompanied rising sea-surface temperatures, indicating a consistent warming and moistening trend of the marine atmosphere over the period 1987-1998. Thus, overall, at least in the vicinity of Ireland, it seems likely that decreased sunshine hours (increased cloudiness) may result from the increased temperatures associated with global warming. 

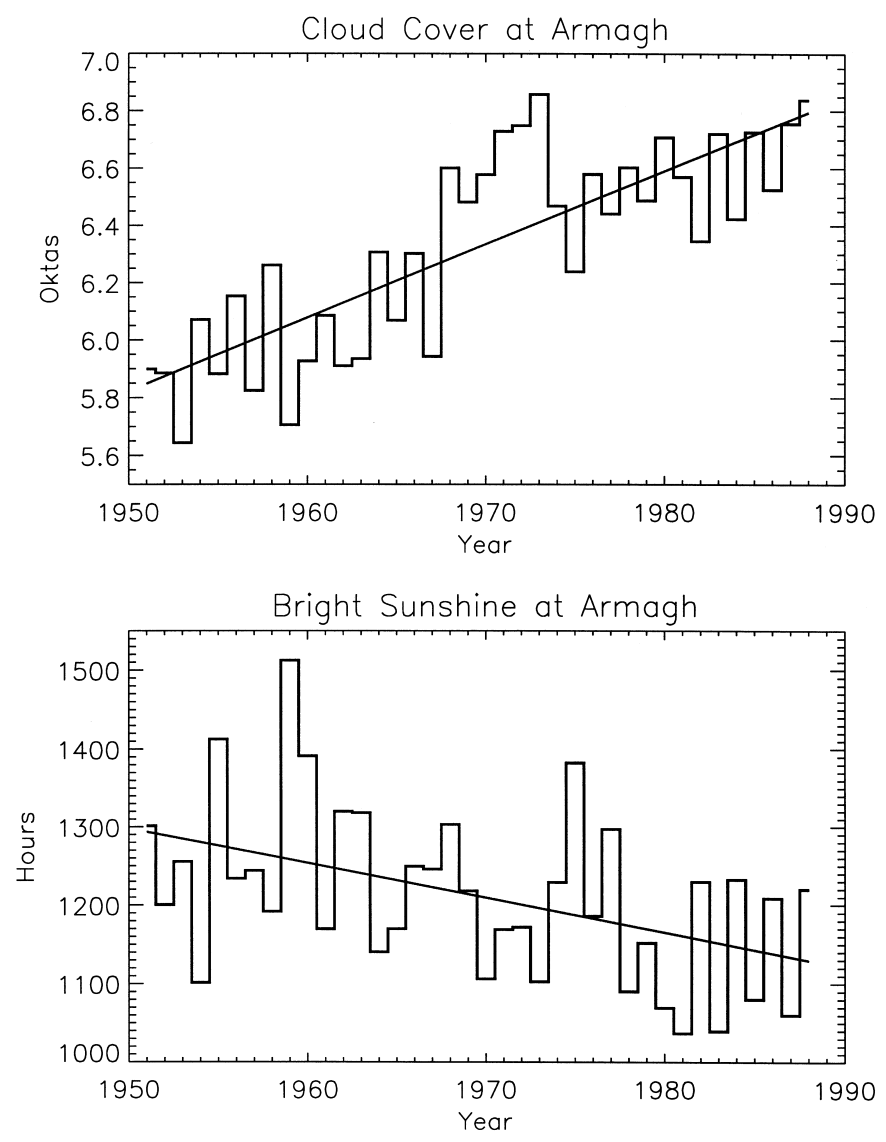

Figure 6. Total annual sunshine hours (bottom) and mean synoptic cloud cover (top) at Armagh for the period 1951-1988. Superimposed on each plot is a least squares linear fit

\section{COMPARISON OF SUNSHINE FACTOR OVER IRELAND WITH CLOUD FACTOR FROM SATELLITES}

To assess further whether sunshine data is a good proxy for clouds, this data was compared with the recently released ISCCP D2 dataset. Formerly, cloud data from satellites and ground stations differed, but in the new D2 dataset low cloud and cirrus detection has been implemented (Rossow et al., 1996) and has been found to be highly correlated with ground observations (Seze et al., 1986). Though other factors could be involved, for our purposes, the sunshine factor $\left(F_{\mathrm{s}}\right)$ is converted into equivalent cloud factor $\left(F_{\mathrm{c}}\right)$ by the equation $F_{\mathrm{c}}=1-F_{\mathrm{s}}$.

It is a straightforward procedure to make a direct comparison of satellite cloud factors over the relatively extended areas ( $280 \mathrm{~km}$ resolution, equal area boxes) provided by the ISCCP project, and the sunshine factor from ground-based observations. The cloud factors from the ISCCP (Rossow et al., 1996), resulting from fits of computer models to the basic infra-red and optical observations, were determined for fifteen different cloud types at three different levels (low, medium and high), and covered the period July 1983-August 1994. Here we were only concerned with the total cloud factor as this was the most relevant for comparison with sunshine factors.

The boxes which cover Ireland are those centred at the following north latitudes and east longitudes: $51.25 / 350.00,51.25 / 354.00,53.75 / 349.41$ and 53.75/353.65. The position of these boxes relative to the four ground-based stations, is indicated in Figure 1. The mean monthly cloud factor in these four boxes was compared to the mean monthly sunshine factor for the four Irish sites. In addition, the correlation 
coefficients of the Irish cloud data were determined and compared to those of the wider north Atlantic and global regions in order to assess the usefulness of the Irish data (both cloud and sunshine) as a proxy for conditions over wider areas.

Figure 7 shows the mean cloud factor per month over the period July 1983-August 1994 together with the mean sunshine factor per month for the four Irish stations. It is immediately obvious that, as expected, there is a strong anti-correlation between the cloud factor and sunshine factor over Ireland which is particularly clear in the spring-early summer months when the number of sunshine hours was greatest. The correlation coefficient was -0.93 , equivalent to a probability of occurrence by chance of less than $0.1 \%$.

Figure 8 shows the mean cloud factor for each month in the period July 1983-August 1994 over the four satellite boxes, against the mean sunshine factor for the four Irish sites. In the upper panel, data obtained during the years 1992-1994 following the eruption of Mount Pinatubo in the Philippines, are shown by filled circles. It is evident that the increased turbidity of the atmosphere at this time reduced the sunshine factor compared to the cloud factor. When the data for 1992-1994 are removed, the scatter is reduced and the correlation coefficient rises from $-0.71(p<0.1 \%)$ for all data (132 points) to -0.82 $(p<0.1 \%)$ for summer months, excluding 1992-1994 (50 points). These results verified our basic underlying assumption that long-term sunshine records can be used to give meaningful information on cloud factors prior to the availability of satellite observations.

\section{COMPARISON OF SATELLITE CLOUD FACTORS OVER IRELAND AND MORE EXTENDED REGIONS}

Following the confirmation that satellite cloud factors over Ireland correlate well with sunshine factors, we were interested to ascertain if the cloud factor over Ireland was representative of a wider global region. A good correspondence between cloud factor over Ireland and, say, the north Atlantic region might be expected in view of the prevailing westerly winds which carry the Atlantic weather systems across Ireland.
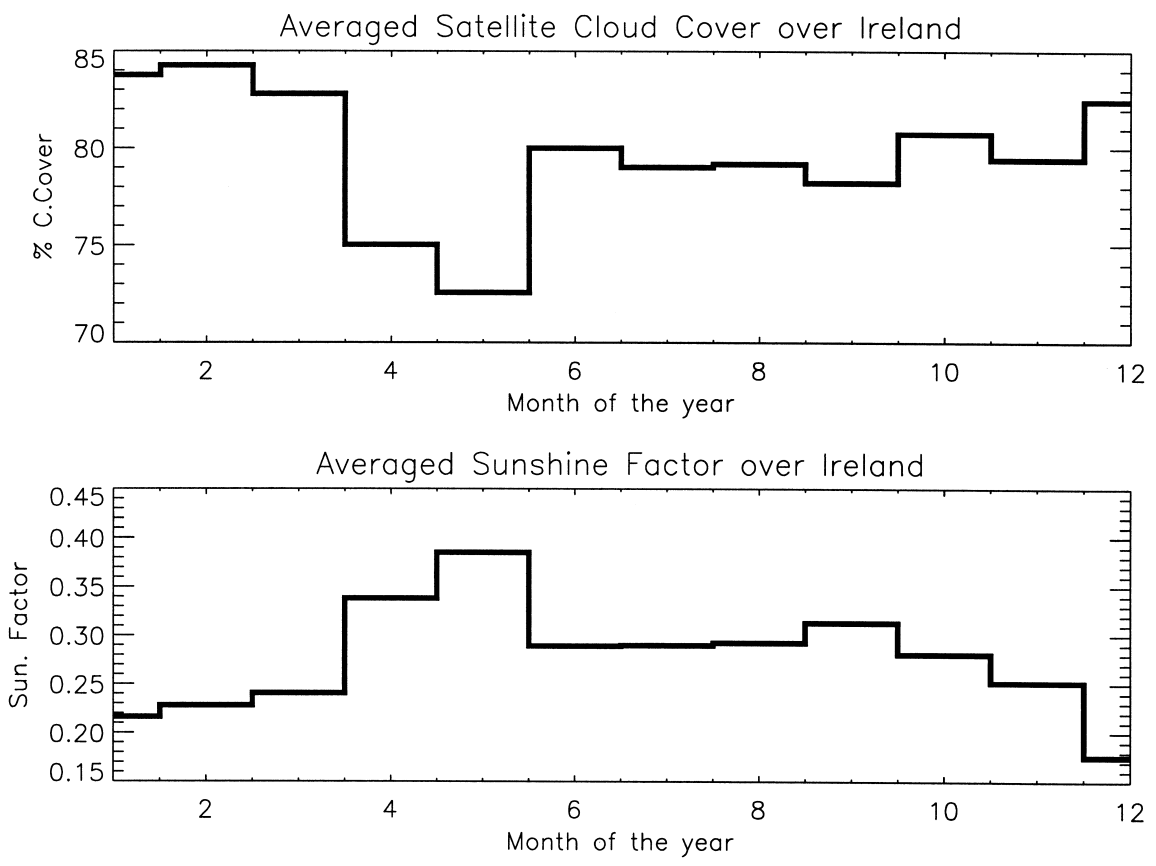

Figure 7. Averaged monthly satellite cloud cover variation over Ireland during the period 1983-1994 and averaged monthly sunshine factor over Ireland during the same period 

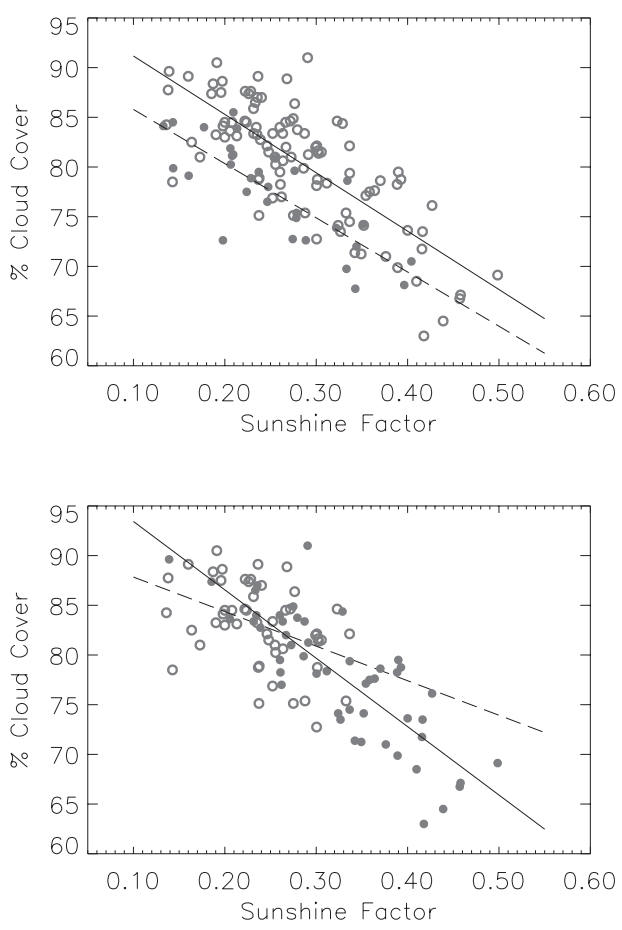

Figure 8. Correlation between the monthly mean Irish sunshine factor and the satellite cloud factor over Ireland for the period 1983-1994. Top panel: all data is plotted with the data possibly affected by the Mount Pinatubo eruption (1992-1994) marked with filled circles. Two regression lines are plotted, one for the months unaffected by volcanic eruptions (solid line) and one for the possibly affected months (broken line). In the lower panel, the data possibly affected by volcanic eruptions have been removed and a distinction between spring-summer (A, M, J, J, A, S, filled circles) and autumn-winter (O, N, D, J, F, M, open circles) is made. Again both regression lines are plotted (solid summer; broken winter)

The zones chosen for comparison with cloud factors over Ireland were: (1) the north Atlantic region, latitudes $40^{\circ}-60^{\circ} \mathrm{N}$ and longitudes $285^{\circ}-360^{\circ} \mathrm{E}$; (2) high mid-latitudes in both northern and southern hemispheres, latitudes $40^{\circ}-60^{\circ} \mathrm{N} \& \mathrm{~S}$, (3) mid-latitudes in both hemispheres, latitudes $22.5^{\circ}-60.0^{\circ} \mathrm{N} \& \mathrm{~S}$; (4) the poles, latitudes $>60^{\circ} \mathrm{N} \& \mathrm{~S}$; (5) the tropics, latitudes $<22.5^{\circ} \mathrm{N} \& \mathrm{~S}$; (6) a region used by Svensmark and Friis-Christensen (1997) (SFC Zone) which includes all ocean regions outside the tropics, latitudes $>22.5^{\circ} \mathrm{N} \& \mathrm{~S}$; (7) the whole Earth. The correlation coefficients for the respective annual and monthly data sets with the data for Ireland are given in Table II separately for regions over: oceans, land and ocean + land. In addition, after the correlation coefficient, we give the probability of occurrence by chance of this degree of correlation. It is noted, not unexpectedly, that there is a high degree of correlation between the cloud factor over Ireland and the north Atlantic generally. What is perhaps more surprising, is that there is significant correlation between the cloud factor over Ireland and that over the high mid-latitude ocean region N\&S and with the mid-latitudes over oceans generally as well as globally. However, the correlation with all land areas is not significant regardless of the latitude range. The high degree of correlation is evident in both annual and monthly data.

Figure 9 shows the monthly cloud factors for Ireland and the various ocean zones described above, smoothed with a 12-month running mean to eliminate seasonal effects. The broad similarity in shape of cloud factor variation with time over Ireland and that in the north Atlantic, mid-latitude and global ocean regions is clearly seen in the figure. A slight downward trend in cloud factor over most of the zones excluding the poles can be seen over the period covered by the data. This study suggests, therefore, that sunshine data from areas such as Ireland which lie close to the margins of a large ocean and in the direction of the prevailing wind, can give useful information on long term cloud behaviour, not only for Ireland but also over much more extended maritime regions. As clouds are important, both for their 
SUNSHINE RECORDS, IRELAND

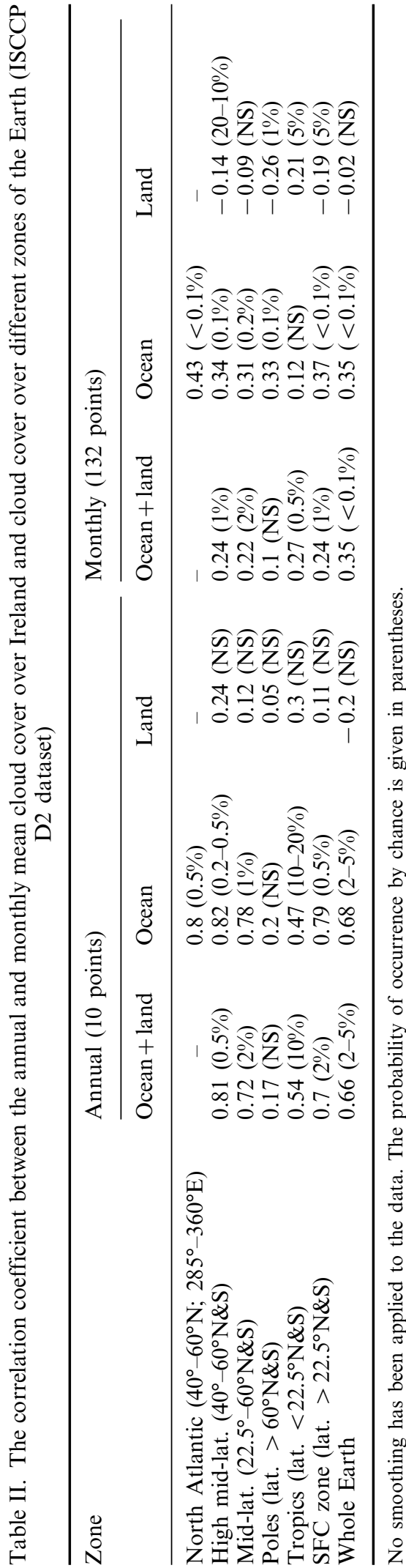



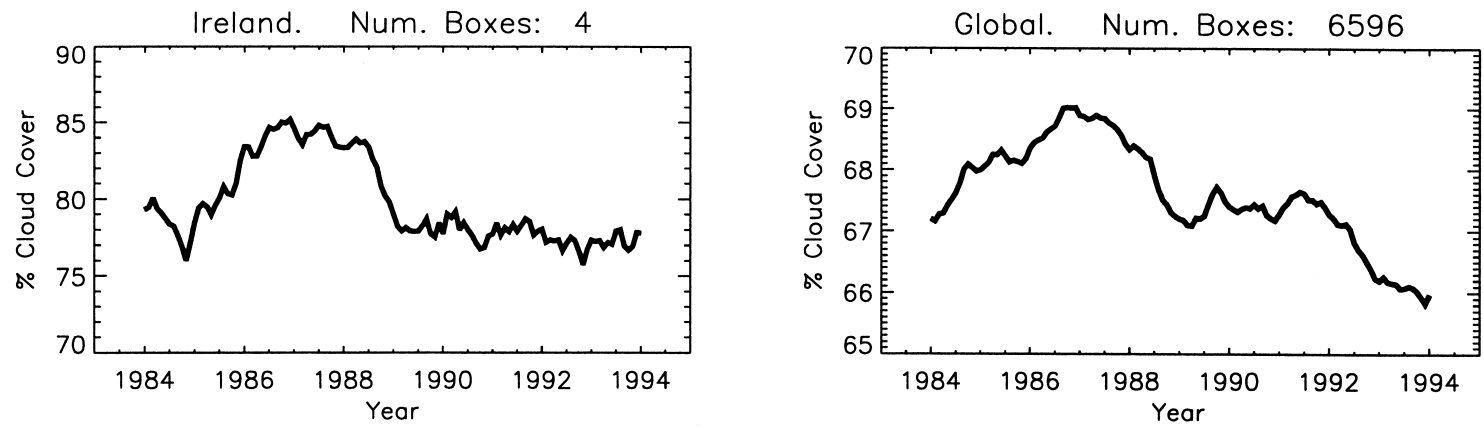

Poles. Num. Boxes: 882
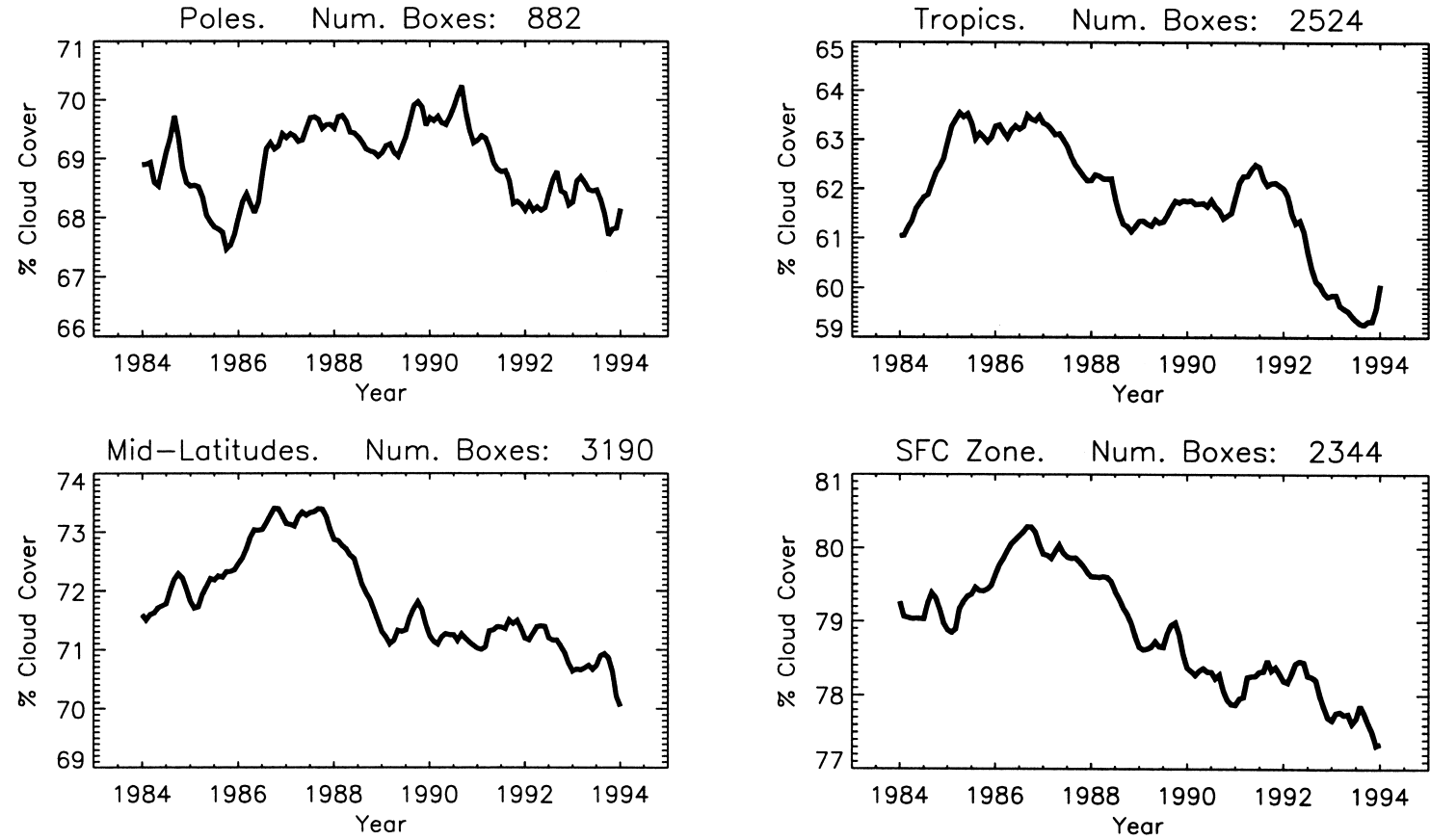

N. Atl. Ocean. Num. Boxes: 235
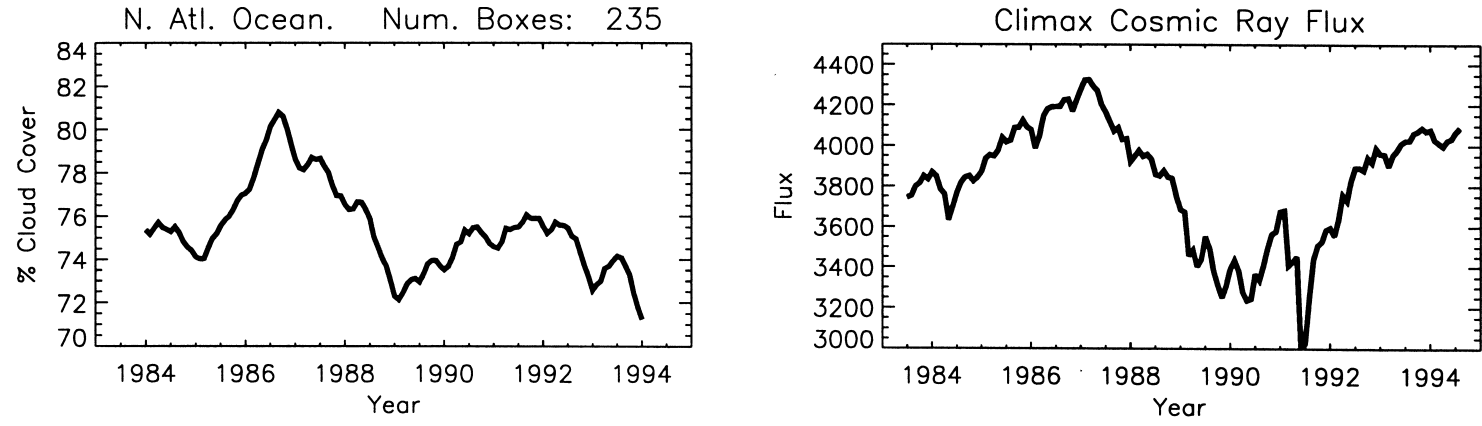

Figure 9. Twelve-month running mean of the ISCCP D2 monthly total cloud cover over various areas of the Earth (see description in the text), over land and ocean. The sixth and seventh panels cover ocean areas only. Note the similar behaviour of the Irish data and larger areas like the North Atlantic Ocean, the SFC zone and the high mid-latitude areas. In Table II, correlation coefficients and statistical significance are stated for the correlation between data for each area (without the 12-month filter) and the Irish cloud factor. The number of 2.5 degree square equal area boxes from the ISCCP dataset used for each region is shown in the top right hand corner 
albedo and their reflectance of the Earth's infra-red radiation, any persistent change in cloudiness could seriously affect the global energy budget. Thus computer models of the Earth's climate which do not include the effects of changing cloud factors could be seriously in error when used to predict long-term temperature trends.

\section{CLOUD FACTOR AND COSMIC RAYS}

Svensmark and Friis-Christensen (1997) found a highly significant correlation between the cloud factor over oceans outside the tropics and the cosmic ray flux for the period 1984-1991. This interval bracketed a triangular-shaped maximum in cosmic ray flux which peaked in 1987. Our satellite cloud data extend a further three years to cover the interval 1984-1994.

Figure 9 (bottom right-hand panel) shows the cosmic ray flux from the Climax station neutron monitor (http://ulysses.uchicago.edu/NeutronMonitor/neutron_mon.html). Although this data is measured at a single site, in general the cosmic ray fluxes measured at different places on the Earth's surface are proportional to one another. Therefore the Climax data was chosen as representative because of its longevity. Figure 8 also shows that, whereas the cosmic ray flux and cloud factor in the mid-high latitude and Svensmark regions correlate well during the 1984-1991 period, this correspondence breaks down during the last three years of the cloud data. This result is similarly obvious in Table III where the correlation coefficient between the annual cloud factor and the annual cosmic ray factor are listed for the two periods 1984-1991 and 1984-1994 separately. Whereas a significant correlation was evident in 1984-1991, the correlation drops to non-significant values after 1991. From these results it can be concluded that the correlation between total cloud cover and the mid-high latitude oceans and cosmic ray flux found by Svensmark and Friis-Christensen (1997) does not persist into the period 1991-1994. However, there is now some evidence for a significant correlation between specifically low cloud cover and the cosmic ray flux (see Marsh and Svensmark, 2000; Palle and Butler, 2000).

\section{CORRELATION BETWEEN SUNSHINE FACTOR AND SUNSPOT CYCLE LENGTH}

The length of the sunspot cycle is a parameter which has been shown to vary in a similar way to the Northern Hemisphere temperature over the past 150-200 years (Friis-Christensen and Lassen, 1991; Butler and Johnston, 1996). It is an empirical parameter determined using epochs of maxima and minima found by the secular smoothing procedure used by Gleissberg and from which it is possible to calculate the smoothed sunspot cycle length since 1740 (Gleissberg, 1944; Lassen and Friis-Christensen, 1994).

There is no evident connection between sunshine factor and solar activity when we use sunspot number as an indicator of activity. However, if the solar cycle length is used, a correlation is apparent.

To illustrate this we first determined the mean sunshine factor over individual sunspot cycles. The epochs of minimum activity given by Lassen and Friis-Christensen (1992) were taken, as well as the average sunshine factor data during the interval between the minima. To avoid seasonal effects, it was necessary to average the monthly sunshine factors for an integral number of years (the number closest to the sunspot cycle length at that time was used). The starting month of the cycle is taken as that intermediate between the months of sunspot minima at the beginning and end of the cycle. For instance, for cycle number 19, is can be noted that the minima at the beginning and end of the cycle occurred in July 1954 and March 1965 and that the cycle length given by Lassen and Friis-Christensen (1992) is 10.7 years. The average monthly sunshine factor from May 1954 to April 1965 was used as the mean sunshine factor for this cycle. After averaging in this way the data set was reduced from 117 points to 11 points.

The mean sunshine factors, averaged over individual cycles, were plotted against time in Figure 10 and against sunspot cycle length in Figure 11. In these figures, data for years during which volcanic eruptions were suspected to have caused a reduction of sunshine, have been excluded. The correlation coefficients between the mean sunshine factor and the sunspot cycle length are given in Table IV. They range from 
E. PALLÉ AND C.J. BUTLER

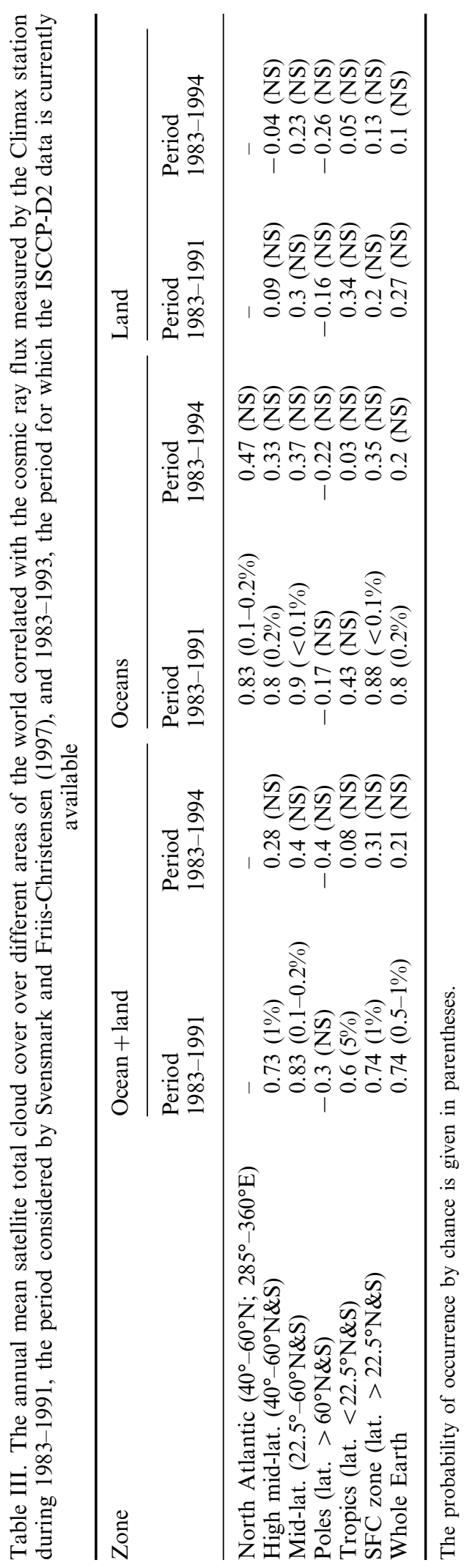



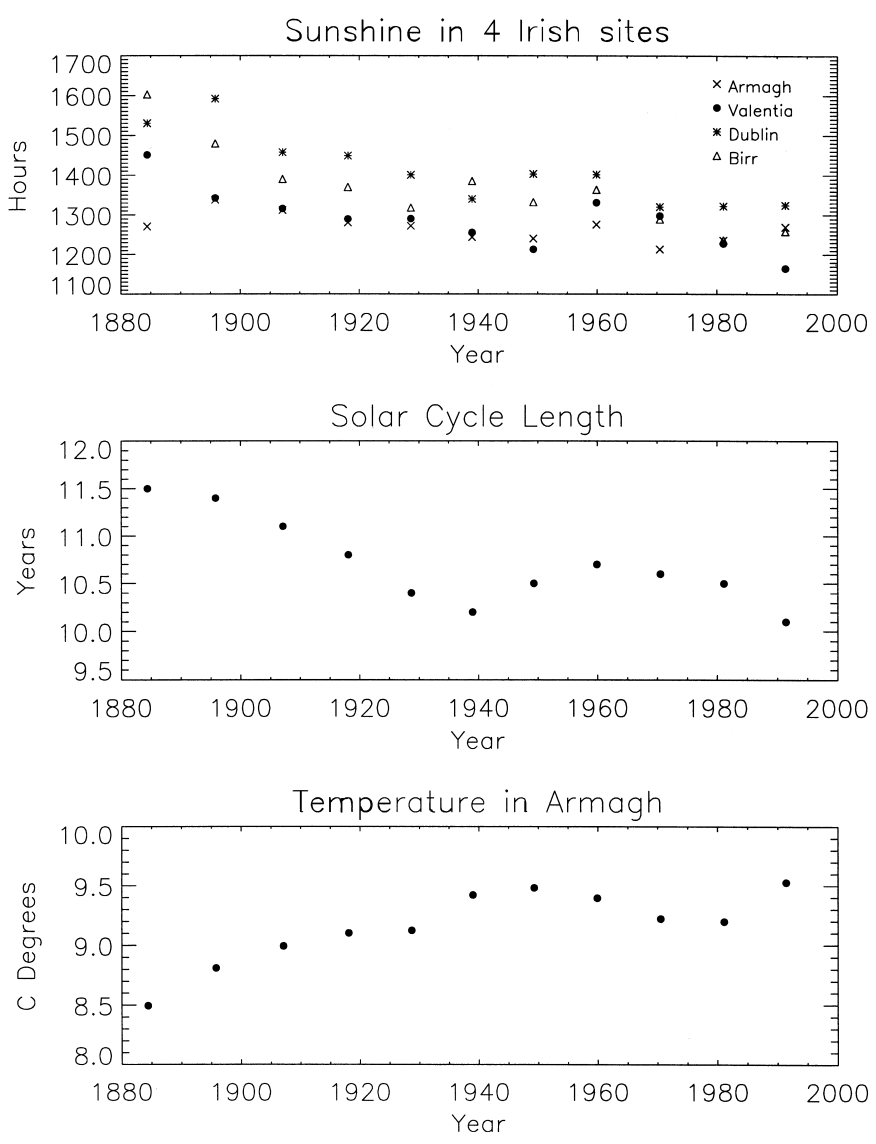

Figure 10. Top: mean annual sunshine per sunspot cycle for four Irish sites. Middle: the sunspot cycle length (smoothed). Bottom: the mean annual temperature at Armagh per sunspot cycle

0.5 for Armagh to 0.84 for Dublin and for three of the stations are significant with a probability of occurrence by chance of less than $2 \%$ and less than $0.5 \%$ when the data for years during and following volcanic eruptions are excluded (see Table V).

The effect that a volcanic explosion will have on the atmosphere and therefore on the sunshine records is difficult to establish quantitatively. The technique used here was to examine the data for the four stations and remove the data for those years during which a volcanic explosion occurs, plus the years immediately following the eruption, if a decrease in sunshine occurs simultaneously with the eruption in the data for all four stations. If the decrease is seen in only some of the stations, the data for that year is not removed from the data set.

Figure 10 also shows the variation of the solar cycle length during the same period and the mean temperature at Armagh Observatory. As previously found by Butler and Johnston (1996), there was a high degree of correlation between the mean air temperature at Armagh and the solar cycle length $(r=0.8,<0.1 \%$ significance level) with higher temperatures corresponding to shorter cycles. Taken at face value, these figures suggest that shorter sunspot cycles are accompanied by reduced sunshine factors (increased cloudiness) over Ireland. This trend goes in the opposite direction to what would be expected if short sunspot cycles were associated with increased activity levels and thereby reduced cosmic ray fluxes, and reduced cosmic ray fluxes were associated with reduced cloudiness (increased sunshine hours). 

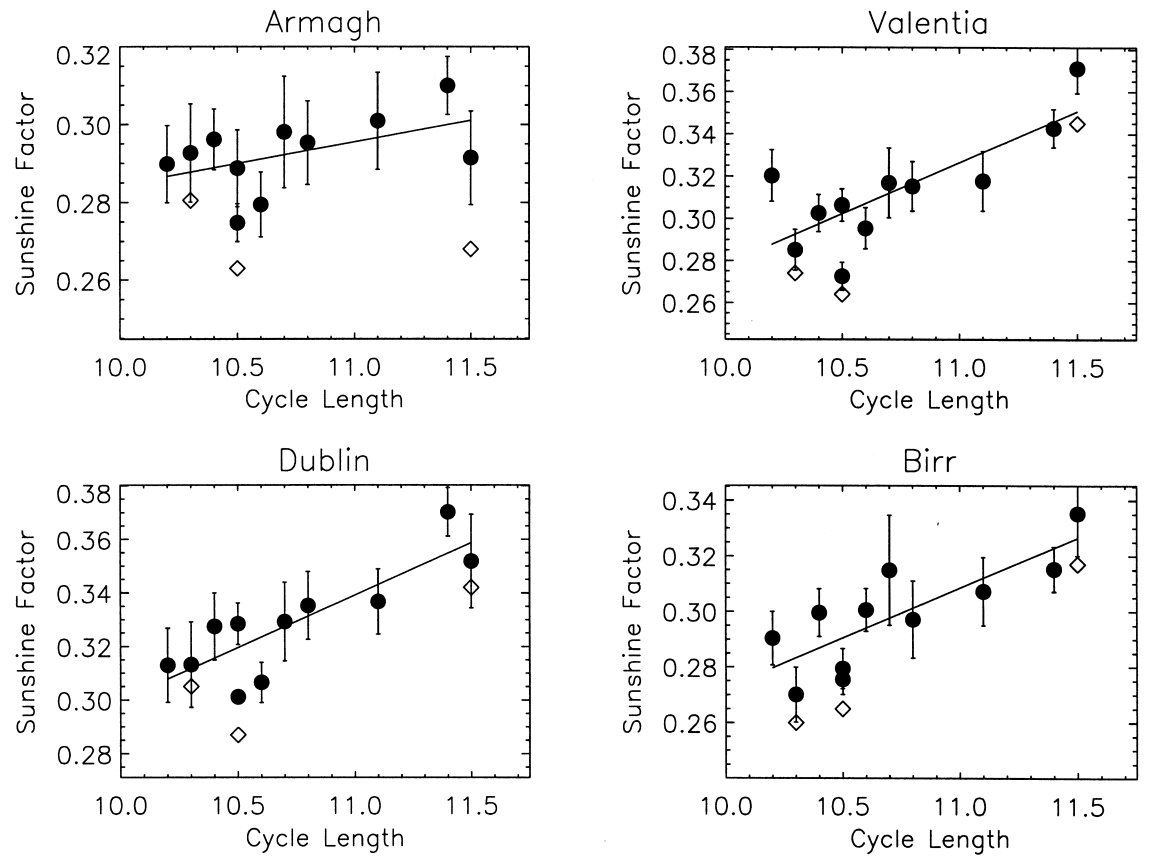

Figure 11. The annual sunshine factor for four Irish sites, averaged over the individual sunspot cycles, plotted against the sunspot cycle length. Data possibly affected by volcanic eruptions are shown with open symbols. The filled symbols above the open symbols exclude possible volcanic effects

Table IV. The correlation coefficient between the averaged sunshine factor during a sunspot cycle and the sunspot cycle length for the four Irish sites, before and after the exclusion of data possibly affected by volcanic eruptions (see Table V)

\begin{tabular}{lll}
\hline Site & $\begin{array}{l}\text { Correlation } \\
\text { coefficient }\end{array}$ & $\begin{array}{l}\text { Probability of } \\
\text { occurrence chance }\end{array}$ \\
\cline { 2 - 3 } & All data & \\
\hline Armagh & 0.12 & ns \\
Valentia & 0.7 & $1.0-2.0 \%$ \\
Dublin & 0.75 & $0.5-1.0 \%$ \\
Birr & 0.7 & $1.0-2.0 \%$ \\
& Affected data & \\
& removed & \\
\hline Armagh & 0.5 & $10.0 \%$ \\
Valentia & 0.78 & $0.2-0.5 \%$ \\
Dublin & 0.84 & $<0.1 \%$ \\
Birr & 0.8 & $0.1 \%$ \\
\hline
\end{tabular}

If the explanation for the overall falling trend in sunshine factor given in Section 4-namely, that rising sea-surface temperatures are accompanied by rising water vapour content over the oceans, thereby leading to increased cloudiness - is correct, then the apparent correspondence between sunspot cycle length and sunshine factor follows naturally as a result of the known correspondence between sunspot cycle length and mean Northern Hemisphere temperature (Friis-Christensen and Lassen, 1991). In this case, a reduced sunshine factor over the oceans is seen to accompany shorter sunspot cycles as a result of the correspondence between sunspot cycle length and temperature, and sea surface temperature and atmospheric water vapour content. 
Table V. Prominent volcanic eruptions during the period 1880-1995 and the Dust Veil Index (DVI) for each eruption (Wilson, 1997)

\begin{tabular}{llll}
\hline Eruption & Year & $\begin{array}{l}\text { Data } \\
\text { removed }\end{array}$ & DVI \\
\hline Krakatoa & 1883 & 1883 & 1000 \\
& & 1884 & \\
Ritter, Bandai San & 1885 & 1886 & 800 \\
St. Helens & 1980 & 1889 & 500 \\
El Chichon & 1982 & 1981 & 800 \\
Nevado Ruiz & 1985 & 1983 & - \\
Pinatubo & 1985 & 1000 \\
& 1991 & 1986 & \\
\hline
\end{tabular}
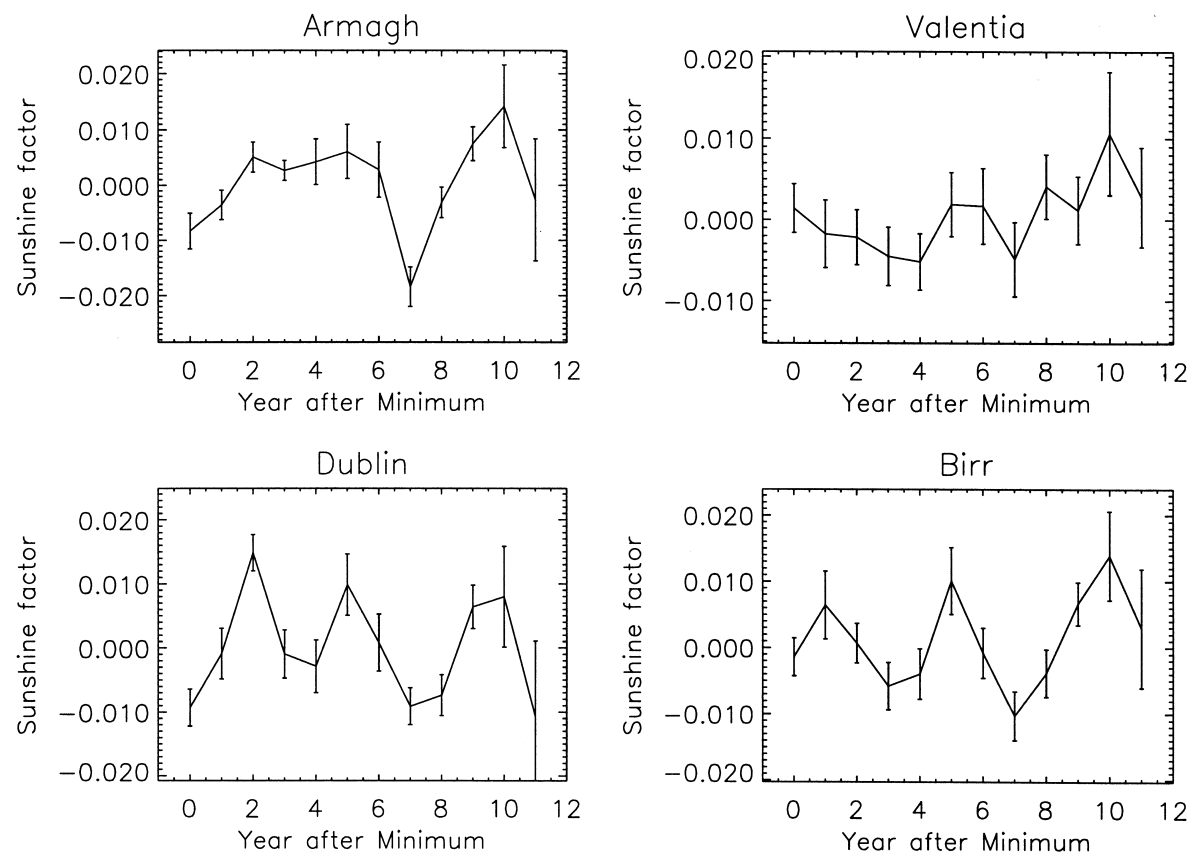

Figure 12. The mean sunshine factor for the four Irish sites against the interval since the previous sunspot minimum. Each point represents the mean of ten annual values and the error bars indicate the standard error of the mean $\sqrt{\Sigma_{i}\left(x_{i}-\bar{X}\right)^{2} / N(N-1)}$. The data covers the period $1881-1997$

\section{SUNSHINE FACTOR OVER THE SCHWABE ( 11-YEAR) ACTIVITY CYCLE}

If cosmic rays are important in the formation of clouds on Earth, then it could be expected that the cloud factors (and thereby the sunshine factors) would vary during the solar cycle. To examine the dependence of annual sunshine with phase of the sunspot cycle, Figure 12 shows the average annual total sunshine hours in the four stations during the period (1881-1997) against the number of years since the previous 

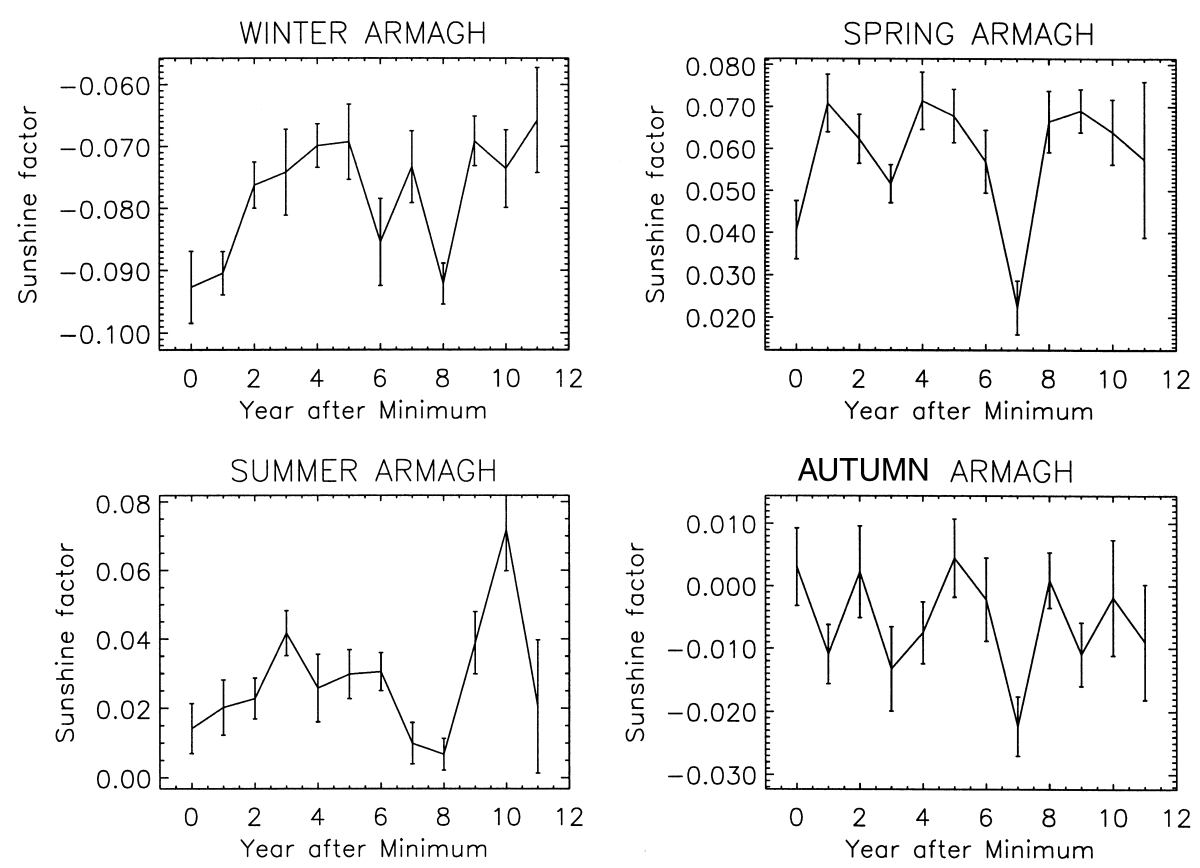

Figure 13. Seasonal plots for Armagh. Note the presence of the dips 7 years after sunspot minimum in all plots in Figures 12 and 13

sunspot minimum. The sunshine data have been previously detrended. In addition, the data for those years during which volcanic effects were identified have been omitted. In Figure 12, mean values are shown for each year after the sunspot minimum, with error bars indicating the standard error of the mean. If the solar cycle had no influence at all on the cloud factor, a random distribution would be expected, but this does not appear to be the case.

The number of hours of sunshine appears to have a conspicuous dip seven years after minimum and a sharp peak shortly before minimum. This behaviour is suggested in the annual data for all four sites and the seasonal data for Armagh (see Figure 13). To assess the significance of these similarities and the significance of the dips, the Student $t$-test and the ANOVA (analysis of variance) tests were used. The ANOVA test (Statsoft, 1997) confirms that the shapes of the curves for all sites are similar; however this could have been expected in view of their geographical proximity. Only the dips in the Armagh curves are statistically significant at the $90 \%$ level. It is possible that long-lived effects (in excess of 3 months) which link the sunshine factor in different seasons (e.g. the North Atlantic Oscillation; Wheeler and Mayes, 1997), rather than cosmic rays, could be responsible for this seasonal similarity.

\section{FORBUSH DECREASES AND SUNSHINE LEVELS}

The occurrence of sudden dips in the cosmic ray flux following flare activity on the Sun, known as Forbush decreases, are well known. In general, these decreases occur on a time-scale of several hours and levels return to normal within a few days. Thus it is difficult, with daily data, to see the full amplitude of the Forbush decrease. Nevertheless, when many such Forbush decreases are stacked together as can be seen in Figure 14, a significant decrease in the mean daily cosmic ray flux which gradually, over 5-10 days, returns to its former level. The Forbush decreases are believed to arise from a disturbance in the interplanetary magnetic field produced by particle emission from the initial solar outburst. They are associated with a strong disturbance in the geomagnetic field indices $a a$ and $A_{\mathrm{p}}$. If the cosmic ray flux 

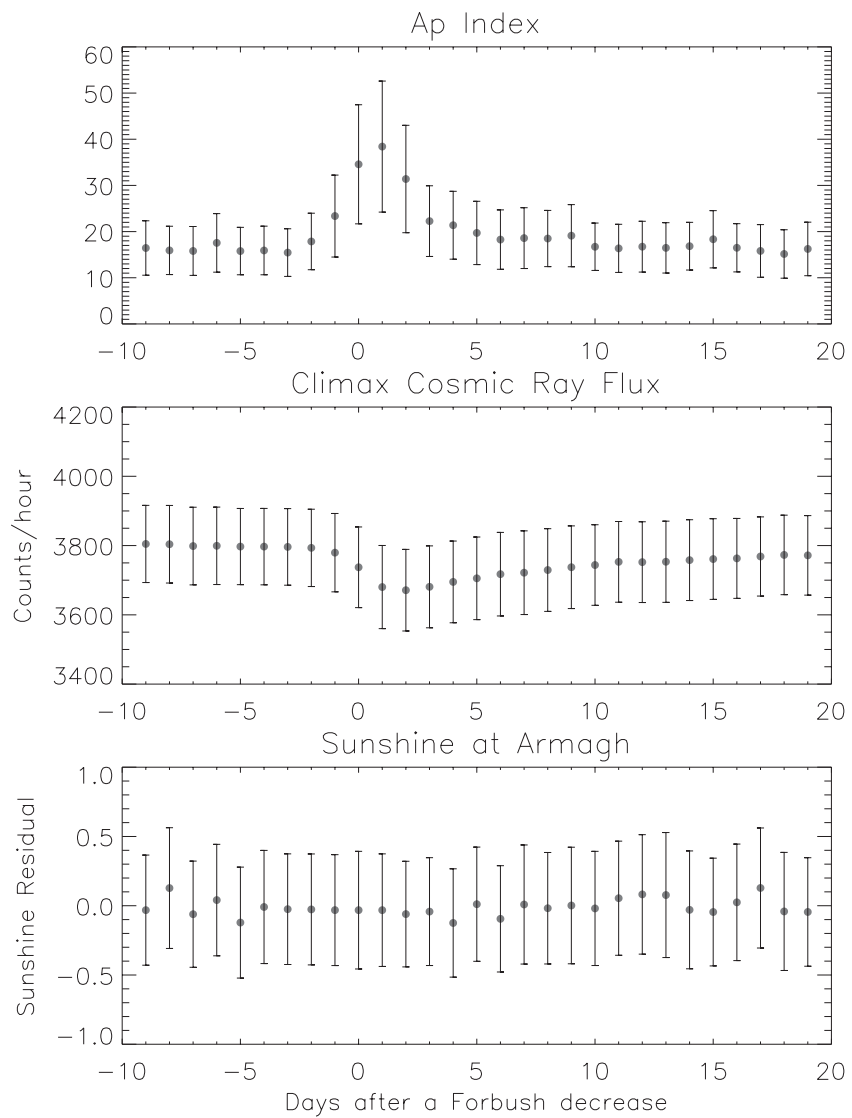

Figure 14. Daily means of the geomagnetic Ap Index (Mayaud, 1980), the Climax cosmic ray flux and the residual from the mean sunshine hours in Armagh during the period 10 days before to 20 days after a Forbush decrease event. An increase in the Ap index is followed by a decrease in cosmic ray flux, but no effect is seen in sunshine hours. The residual sunshine hours was plotted (described in the text) to remove any seasonal effect

influences the cloud factor on Earth as has been proposed, then it might be expected that Forbush decreases would, on average, be associated with decreased cloud (increased sunshine) levels, as found by Pudovkin and Veretenenko (1995).

For the period since 1951 the daily sunshine data for Armagh were entered onto the computer. If the mean sunshine level for the appropriate day of the year are first subtracted (see Figure 3) from the sunshine hours observed, it might be expected to see some evidence for an increase in the average sunshine following the Forbush decrease. Figure 14 shows no evidence of this behaviour in the mean curve for over 250 Forbush decreases measured at Mt. Washington station and listed by the National Geophysical Data Center (NGDC) (http://www.ngdc.noaa.gov/stp/stp.html).

We repeated the experiment using the selected Forbush decreases published by Pudovkin and Veretenenko (1995), but again no significant increase or decrease was detected. This negative result provides no support for the supposed modulation of cloud factors by galactic cosmic rays; however, it may have been over-optimistic to expect such a highly stochastic parameter as Irish sunshine and data of such crude time resolution as one day, to show any influence of short transient phenomena like Forbush decreases.

\section{CONCLUSIONS}

The sunshine data over the period 1881-1998, from four Irish stations were analysed with the following conclusions. 
A gradual decrease in the number of sunshine hours was observed since records began in 1881. For the one site where contemporary sunshine and synoptic cloud records are present we found that the decline in sunshine was consistent with the observed trend in cloud cover. This could be explained by increased cloudiness following higher evaporation rates as sea temperatures rose during the 20th century.

Through comparison with satellite cloud measurements over Ireland it was established that sunshine factor is a good proxy for cloudiness. Thus it is reasonable to use the duration of bright sunshine to indicate long term variations in cloud factor before satellite cloud data was obtained.

This analysis indicates that, over the period 1984-1994, the satellite cloud factors over Ireland correlated well with cloud factors over larger areas, such as the North Atlantic, the mid-high latitude oceans generally and even globally. No correlation is found with satellite cloud factors over extensive land areas.

A correspondence between the number of sunshine hours and the length of the sunspot cycle is indicated.

There was no significant correlation between sunshine factor and cosmic ray flux over the period since 1950 during which the cosmic ray flux has been measured. Nor is there a statistically significant trend in the sunshine factor over the Schwabe sunspot cycle, though a dip at seven years past minimum (three years past maximum) and a peak just before minimum seem to be common features.

There were no significant effects on the sunshine factor following Forbush decreases in cosmic rays.

\section{ACKNOWLEDGEMENTS}

The sunshine data for Dublin, Birr and Valentia Island/Cahirciveen were kindly provided by D. Fitzgerald of Met Eireann, Dublin. The cloud D2 datasets were obtained from the NASA Langley Research Center EOSDIS Distributed Active Archive Center. Also we would like to thank Dr S.H. Larsen, Dr K. O'Brien, Dr B. Bromage and Dr G. McCormac for discussions and M. Murphy for assistance with computing. Research at Armagh Observatory is grant-aided by the Department of Culture, Arts and Leisure for Northern Ireland.

\section{REFERENCES}

Angell JK. 1990. Variations in United States cloudiness and sunshine duration between 1950 and the drought year of 1988. Journal of Climate 3: 296-308.

Angell JK, Korshover J, Cotton GF. 1984. Variation in United States cloudiness and sunshine, 1950-82. Journal of Climate and Applied Meteorology 23: 752-761.

Butler CJ, Hoskin MA. 1987. The archives of Armagh Observatory. Journal of History of Astronomy 18: $295-307$.

Butler CJ, Johnston DJ. 1996. A provisional long mean air temperature series for Armagh Observatory. Journal of Atmospheric and Solar-Terrestrial Physics 58: 1657-1672.

Casey KS, Cornillon P. 1999. A comparison of satellite and in situ based sea surface temperature climatologies. Journal of Climate 12(6): $1848-1863$.

Chagnon SA. 1981. Midwestern cloud, sunshine and temperature trends since 1901: possible evidence of jet contrail effects. Journal of Applied Meteorology 20: 496-508.

Dukes M, Eden P. 1997. Phew! What a scorcher: weather records and extremes. In Climates of the British Isles, Hulme M, Barrow E (eds). Routledge: London; 262-293.

Friis-Christensen E, Lassen K. 1991. Length of the solar cycle: an indicator of solar activity closely associated with climate. Science 254: $698-700$.

Gleissberg W. 1944. A table of secular variations of the solar cycle. Terrestrial Magnetism and Atmospheric Electricity 49: 243.

Henderson-Sellers A. 1989. North American total cloud amount variations this century. Paleogeography, Paleoclimatology, Paleoecology 75: 175-194.

Jones PA, Henderson-Sellers A. 1992. Historical records of cloudiness and sunshine in Australia. Journal of Climate 5: 260-267.

Kelly PM, Jones P, Briffa K. 1997. Classifying the winds and weather. In Climates of the British Isles, Hulme M, Barrow E (eds). Routledge: London; 153-169.

Kernthaler SC, Toumi R, Haigh JD. 1999. Some doubts concerning a link between cosmic ray fluxes and global cloudiness. Geophysical Research Letters 26(7): 863-865.

Kristjansson JE, Kristiansen J. 2000. Is there a cosmic ray signal in recent variations in global cloudiness and cloud radiative forcing? Journal of Geophysical Research 105: 11851-11863.

Lamb HH. 1977. Climate: Present, Past and Future, v. 2, Climatic History and Future. Methuen: London.

Lassen K, Friis-Christensen E. 1992. Solar activity parameters used in Geophysical studies at DMI. Danish Meteorological Institute Technical Report. 
Lassen K, Friis-Christensen E. 1994. Variability of the solar cycle length during the past five centuries and the apparent association with terrestrial climate. J Atmos Sol Terr Phys 57: 835-845.

Marsh ND, Svensmark H. 2000. Low cloud properties influenced by cosmic rays. Physical Review Letters 85(23): 5004-5007.

Mayaud PN. 1980. Derivation, meaning and use of the geomagnetic indices. Geophysical Monograph 22. AGU, Washington DC.

Norris JR. 1999. On trends and possible artifacts in Global ocean cloud cover between 1952 and 1995. Journal of Climate 12: $1864-1870$.

Observers Handbook, 4th edn. 1982. UK Meteorological Office (eds). Her Majesty's Stationery Office, London.

Palle E, Butler CJ. 2000. The influence of cosmic rays on terrestrial clouds and global warming. Astronomy and Geophysics 41: $18-22$.

Pudovkin MI, Veretenenko SV. 1995. Cloudiness decreases associated with Forbush-decreases of galactic cosmic rays. Journal of Geophysical Research 57: 1349-1355.

Raju ASN, Kumar KK. 1982. Comparison of point cloudiness and sunshine derived cloud cover in India. Pure and Applied Geophysics 120: 495-502.

Ramanathan V, Cess RD, Harrison EF, Minnis P, Barkstrom BR, Ahmad E, Hartman D. 1989. Cloud-radiative forcing and climate. Results from the Earth Radiation Budget Experiment. Science 243: 57-63.

Reid GC. 1987. Influence of solar variability on global sea surface temperatures. Nature 129: 142-143.

Rossow WB, Walker AW, Beuschel DE, Roiter MD. 1996. International Satellite Cloud Climatology Project (ISCCP): Documentation of New Cloud Datasets. WMO/TD-No. 737. World Meteorological Organization: Geneva.

Russak V. 1990. Trends of solar radiation, cloudiness and atmospheric transparency during recent decades in Estonia. Tellus 42B: $206-210$.

Seze G, Drake F, Desbois M, Henderson-Sellers A. 1986. Total and low cloud amounts over France and southern Britain in the summer of 1983: comparison of surface-observed and satellite retrieved values. International Journal of Remote Sensing 7: $1031-1050$

Stanhill G. 1998. Long-term trends in, and spatial variation of, solar irradiance in Ireland. International Journal of Climatology 18: $1015-1030$

Statsoft Inc. 1997. Electronic Statistics Textbook, Tusla, OK [http://www.statsoft.com/textbook/stathome.html] [accessed April 2000].

Sun B, Groisman PY. 2000. Cloudiness variations over the former soviet union. International Journal of Climatology 20: 1097-1111.

Svensmark H. 1998. Influence of cosmic rays on Earth's climate. Physical Review Letters 81: 5027-5030.

Svensmark H, Friis-Christensen E. 1997. Variations of cosmic ray flux and global cloud coverage. A missing link in solar-climate relationships. Journal of Atmospheric and Solar-Terrestrial Physics 59: 1225.

Wentz FJ, Schabel M. 2000. Precise climate monitoring using complementary satellite data sets. Nature 403: 414-416.

Wheeler D, Mayes J. 1997. Regional Climates of the British Isles. Routledge: London; 343.

Wilson RM. 1997. Evidence for solar-cycle forcing and secular variations in the Armagh observatory temperature records (1844-1992). Journal of Geophyscal Research 103: 11159-11171. 